\title{
El rol de la incoherencia: pedagogía poscolonial y teología en la narrativa de la conquista de la Nueva corónica y buen gobierno
}

The role of incoherence: postcolonial pedagogy and theology in the narrative of the conquest of the Nueva corónica y buen gobierno

\author{
Gonzalo Lamana \\ University of Pittsburgh, Pensilvania, Estados Unidos \\ Contacto: lamana@pitt.edu \\ https://orcid.org/0000-0003-0347-9822
}

\section{Resumen}

Este ensayo estudia aspectos de la narrativa de la conquista de la Nueva corónica y buen gobierno de Guaman Poma de Ayala que han recibido limitada atención. El argumento central es que el objetivo del autor andino era producir un cambio en la forma en que los lectores le daban sentido al mundo que los rodeaba. Para ello, adoptó una estrategia pedagógica: confrontar al lector con aparentes incoherencias, absurdos históricos, para sorprenderlo y que se preguntase, dudase y, finalmente, se diera cuenta de que eran las premisas que tenía sobre la realidad las que hacían que esos elementos pareciesen raros, absurdos o incoherentes, no los elementos en sí. Es decir, eran acertijos, medios de una estrategia con fines decoloniales.

Palabras claves: Felipe Guaman Poma de Ayala; Conquista; Pedagogía decolonial; Teología; Gracia; Milagro

\begin{abstract}
This essay studies some aspects of the narrative of the conquest of Guaman Poma de Ayala's Nueva corónica y buen gobierno that have received limited scholarly attention. Its main argument is that the Andean author's goal was to alter the way in which readers gave meaning to the world in which they lived. To that end, he adopted a pedagogical strategy: he confronted the readers with apparent incoherences and historical absurdities, to surprise them and have them ponder, hesitate and, finally, realize that it was the premises they held about reality that made those elements seem strange, absurd, or incoherent, not the elements themselves. That is, they were riddles, means for a strategy with decolonial ends.
\end{abstract}

Keywords: Felipe Guaman Poma de Ayala; Conquest; Decolonial pedagogy; Theology; Grace; Miracle

Recibido: 21.08 .19

Aceptado: 14.10 .19 
De las dos partes de la Nueva corónica y buen gobierno dedicadas a reescribir la historia prehispánica y el presente colonial del momento, la narrativa polémica de la conquista que se coloca entre ambas parece una de las más directas del texto. Como otros estudiosos han señalado, estas páginas sientan las bases de dos argumentos importantes del libro: la negación de que hubo una guerra justa y la dura crítica a la cristiandad de los españoles. Estos argumentos juegan un papel central en la obra guamanpomiana porque cambian la forma en la que la presencia española debía entenderse en la historiografía colonial. En primer lugar, la conquista del Perú no fue el resultado de un acto militar legítimo, como los autores españoles decían. Como Guaman Poma repetidamente declaró en cuanto a la reacción de los incas ante los conquistadores: "no se defendió y no ubo conquista" y, por lo tanto, los derechos de los pueblos andinos al autogobierno no podían ser ignorados ni pisoteados. En tal sentido, la autoridad de los señores étnicos había sido injustamente suprimida y debía ser restituida. En segundo lugar, los conquistadores se habían comportado de muchas formas excepto como buenos cristianos y no habían traído el cristianismo a los pueblos andinos, sino se habían arrogado una superioridad moral. Por ello, su reivindicación como héroes de una tarea civilizadora era nula (Adorno, 2000, pp. 13-35, 59-61).

Si bien es indudable que muchos pasajes de la narrativa de la conquista sostienen esta interpretación, examino en este ensayo otros elementos que no han recibido la misma atención crítica con la esperanza de contribuir a la extensión del marco de inteligibilidad del libro en su totalidad. Después de todo, la idea de restitución no era tan polémica como podría parecer en retrospectiva sino era, más bien, parte del proyecto político de Las Casas que, en sus obras, sostenía esta idea con los mismos argumentos. Analizo a continuación estrategias narrativas orientadas no hacia la polémica de ideas políticas, sino hacia la pedagogía decolonial. Para ello, me enfoco en elementos que parecen ser falsos, absurdos o contradictorios y, por lo tanto, incoherentes cuando se compara al texto guamanpomiano con la historiografía de su época. Por ejemplo, un lector con un poco de conocimiento de los hechos en cuestión se preguntaría por qué un embajador incaico fue enviado para encontrarse con gente de la que no se había 
sabido nada hasta entonces. Y a la inversa: un lector atento se preguntaría por qué, si los conquistadores eran retratados como saqueadores, ladrones y violadores, se dignificaba a sus jefes y se les llamaba "embajadores". Por último, cualquier lector cristiano habría encontrado difícil reconciliar la intervención de Dios que se manifiesta en el carácter providencial que tiene la conquista y, en particular, en los distintos milagros que ocurren durante la misma, con el hecho de que su resultado fue el fin de "el buen orden" y el comienzo de "el mundo al revés" (p. 411) ${ }^{1}$. Sostengo que estas instancias de aparentes absurdos históricos y de incoherencias argumentales fueron intencionales y tuvieron un fin específico: apuntaban a alterar la manera cómo los lectores le daban sentido al mundo andino colonial en el que vivían. Los elementos desconcertantes del texto tenían como objetivo que los lectores se sorprendiesen, se preguntasen, dudasen y, finalmente, se dieran cuenta de que eran las premisas que ellos tenían sobre la realidad las que hacían que esos elementos pareciesen raros, absurdos o incoherentes, y no los elementos o los hechos en sí. Es decir, Guaman Poma plantea acertijos como medios de una estrategia pedagógica con fines decoloniales.

\section{"Gobernadores" y no "embajadores": la colonialidad expuesta con claridad meridiana}

Comienzo la tarea de darle cuerpo a mi argumento sobre el rol de las incoherencias con el estudio del encuentro entre los "embajadores" inca y español en Tumbes en lo que pudo haber sido una escena de contacto. El hecho de que, según el cronista andino, un "embajador" inca diera la bienvenida a los españoles en Tumbes es la representación de un evento más que distingue a la Nueva corónica. En tanto que la presencia de lo que parecía un espía-emisario aparece en las obras de autores españoles del siglo XVI, nadie lo llamó “embajador" y aún menos planteó un encuentro solemne, como lo hizo Guaman Poma en su crónica ${ }^{2}$. Esta escena se aprecia en el dibujo de la página 377 en el que Francisco Pizarro, Diego de Almagro y Martín Guaman Malque de Ayala, padre del cronista y segunda persona del inca, se encuentran de manera pacífica tal como apunta el texto: "Se dieron pas el rrey enperador de Castilla y el rrey de la tierra deste rreyno del Piru 
Uascar Ynga, lextimo. En su lugar fue su segunda persona y su bizorrey Ayala” (figura 1).

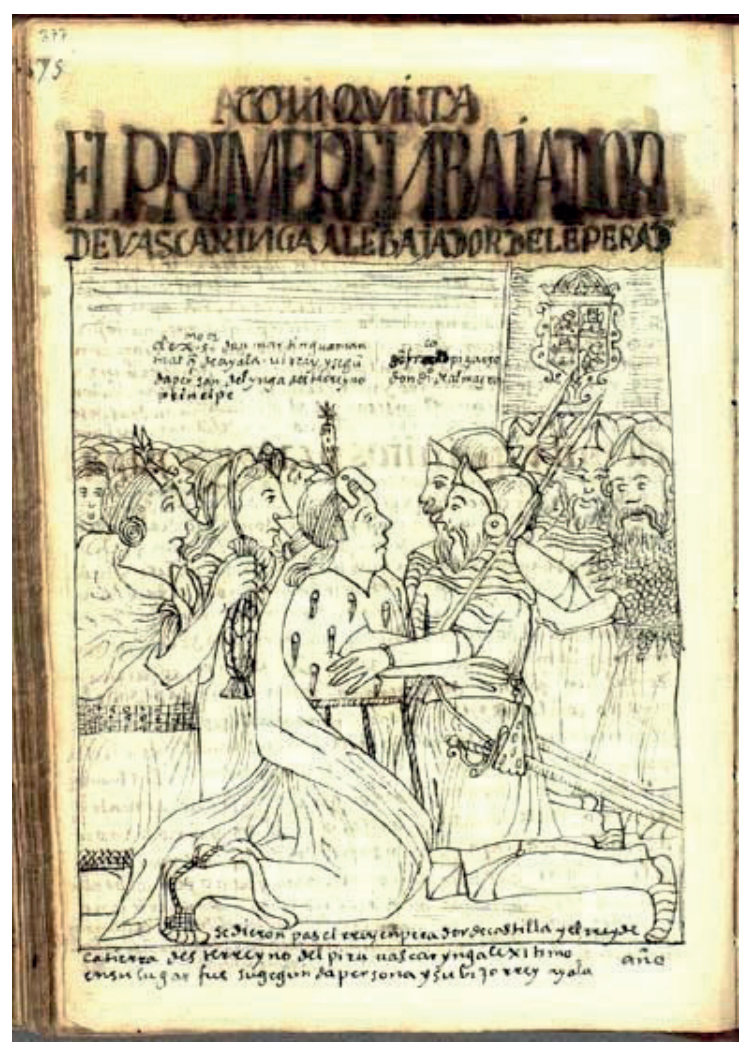

Figura 1. Nueva corónica y buen gobierno (1615), p. 377.

Biblioteca Real de Copenhague, Dinamarca.

Algunos estudios señalan tres fines retóricos que puede haber tenido la presencia de una embajador inca recibiendo a los españoles: i) elevar el linaje de Guaman Poma ante su lector, ya que el embajador era su padre; ii) responder a las representaciones bienintencionadas, pero en última instancia denigrantes, de los pueblos amerindios como sociedades que carecían de los medios y la capacidad para actuar políticamente; y, iii) sostener el argumento de que no hubo ni resistencia ni guerra justa (Adorno, 2000, pp. 29-30). Si bien estos argumentos son razonables, no explican algunos aspectos extraños del encuentro. ¿Por qué 
se envió a alguien a recibir a los extranjeros si nadie sabía quiénes eran o por qué venían? ¿Por qué Guaman Poma los llamó “embajadores” si no sabía si iba a encontrarse con emisarios diplomáticos? Del mismo modo, si llamar al enviado indígena "embajador" podría tener sentido por las razones antes mencionadas, ¿por qué referirse a Pizarro y a Almagro como "embajadores", en especial teniendo en cuenta que en el texto los conquistadores son siempre retratados como depredadores y saqueadores, hombres dominados por la codicia hasta el punto de no dejarlos dormir? ¿Por qué darles un nombre que no solo era engañoso sino también dignificante? (p. 382).

Propongo que el extraño encuentro funcionó como un elemento que sostuvo el objetivo principal de Guaman Poma, que era producir un cambio conceptual profundo del mapa geopolítico: se trataba de corregir la distribución desigual de la conciencia histórica y señaló al lector atento que lo absurdo y lo incoherente no estaba en su texto, sino en el mundo tal y como comúnmente se le daba sentido. Ello señala, a su vez, que la crónica no debía leerse como un medio para establecer la verdad histórica o entrar en polémicas retóricas acerca de la misma, debía leerse más bien como un medio para deshacer formas sólidamente establecidas de dar entender el mundo. La falsedad histórica estridente no era el resultado de un uso ingenuo del género histórico para venderle algo al lector, sino una forma ingeniosa de presentarle y confrontarlo con un enigma.

El absurdo histórico del evento que se empieza a narrar con este dibujo tiene dos componentes por distinguir. El primero es la presencia de un “embajador" inca, lo que apuntaba a una imposibilidad histórica. El segundo era llamar "embajadores" a Pizarro y Almagro, lo cual constituye una imposibilidad conceptual. Hasta cierto punto, la presencia de un embajador inca era coherente con la trama de los capítulos sobre la historia prehispánica, según la cual los pueblos indígenas eran parte de la historia global. Del mismo modo que ellos estaban al tanto del nacimiento de Cristo - y, por eso, uno de los tres reyes magos era indio-, los incas supieron de la existencia del Viejo Mundo y de los españoles en particular ${ }^{3}$. La presencia de un embajador inca corregía así la asimetría implícita o explícita de las narrativas españolas en las cuales los amerindios no 
sabían nada acerca de los españoles y el Viejo Mundo, mientras que los españoles sí estaban al tanto de la existencia de los indios y esto los posicionaba como agentes verdaderos de conquista y colonización. En otras palabras, el encuentro de los embajadores cuestionaba la unilateralidad de la historia global. No había un vacío - fuese político, histórico o teológico - que separara a los españoles de los pueblos indígenas, como lo declaraba el recurso del requerimiento ${ }^{4}$. Se trataba de la forma en que las naciones se relacionaban las unas con las otras en esta época. Como resultado, el tiempo en que vivían tanto españoles como indios se volvía contemporáneo. Esta corrección seguía la misma lógica del rechazo a que el "cristiano lector" aludiera solo a los cristianos y/o españoles (Lamana, 2016).

Ahora bien, aun aquellos lectores que hubiesen entendido el sentido de la presencia (ficticia) de un embajador inca, se habrían quedado pensando en la otra pieza del rompecabezas: los “embajadores” españoles. Esta segunda falacia, tan sorprendente como la primera, también cuestionaba las formas establecidas de darle sentido al mundo, aunque de una manera distinta, ya que no se trataba de una imposibilidad histórica sino conceptual. Guaman Poma llamó ilegales a los actos de los conquistadores y su presencia en el Perú. Repetidamente los retrató como seres movidos, principalmente, por la avaricia y la lujuria. Y, sin embargo, el cronista utilizó el término "embajadores" para designar a los jefes de la compañía de conquista y no "saqueadores", "ladrones", "violadores" o "asesinos". Es contradictorio denigrarlos y dignificarlos como embajadores, es decir, retratarlos como actores que subyugaban y robaban, pero que al mismo tiempo se apegaban al derecho internacional y al buen gobierno. Esta discrepancia era adrede, porque su función era producir un cambio y empujar a que el lector busque una solución. En este caso, la incoherencia revela un doble problema: una parte tenía que ver con la escena local, la otra con la escena en el centro del poder. Si los lectores reflexionaban acerca del comportamiento de los españoles, podían responderse con crímenes y abusos que los caracterizaría como malos cristianos. Si los lectores se hacían la misma pregunta en sentido ético, es decir, cómo deberían haberse comportado, la respuesta era igualmente transparente: como buenos cristianos y con la dignidad de embajadores. Entonces, la solución al aparente rompecabezas 
que plantea este episodio de la Nueva corónica descansa en la teología del siglo XVI: la diferencia entre lo que el cristiano debía hacer y lo que efectivamente hacía. Y la diferencia planteaba la necesidad de actuar de manera acorde con esta toma de conocimiento.

Ahora bien, las discrepancias entre cómo las cosas habían sido y cómo deberían haber sido señalaban incoherencias no de parte de los conquistadores en el Perú, sino en las más altas esferas del poder en la corte, el centro del mundo desde el punto de vista español. Señalar que los conquistadores actuaron de manera bastante lamentable no era algo excesivamente controversial o nuevo. Era parte del repertorio del partido a favor de los indios, como queda abundantemente claro en la Brevísima relación de la destrucción de las Indias de Bartolomé de Las Casas (1552). Pero indicar de una u otra manera que el monarca había enviado "conquistadores" o "gobernadores" y no "embajadores" sí era controversial y distinto, ya que apuntaba directamente al corazón de la colonialidad y revelaba que Guaman Poma veía cómo el colonialismo español permeaba los Andes, desde los conquistadores hasta su más augusta cabeza, el rey.

Como resultado de la discrepancia entre cómo las cosas habían sido y cómo deberían haber sido, cada vez que la Nueva corónica llama a Pizarro o a Almagro "embajador" la incongruencia salta. Frente a esta disonancia cognitiva, los lectores tenían dos opciones: estar de acuerdo con esta afirmación, aunque sabían que era imposible, o sonreír socarronamente con aire de superioridad pensando que estaban ante una idea ridícula. Detrás del pesar o de la sonrisa habría estado el problema que Guaman Poma quería que su lector confrontara. El problema se descubría como una forma europea de darle sentido al mundo frente a la convicción en la (supuesta) diferencia abismal entre la posición de ambas partes. Claramente, los incas no eran los franceses o los ingleses; por lo tanto, hablar de enviar "embajadores" en lugar de "conquistadores" o "gobernadores" al Perú era ridículo.

La Nueva corónica intentó hacer visible el (des)orden colonial. Con ese fin, Guaman Poma hizo que sus lectores enfrentaran las discrepancias entre la forma, el ser y el deber ser de actos y eventos a lo largo del texto. En este caso, 
el encuentro contrapuso dos tipos distintos de imposibles: el imposible factual e histórico (la presencia ficticia de un embajador inca) y el imposible conceptual (los conquistadores como embajadores del rey).

\section{La otra mano de Dios}

Luego de solucionar este acertijo, los lectores de la Nueva corónica tuvieron que enfrentarse a otras aparentes incoherencias en la historia de la conquista. Por un lado, no había habido guerra justa, como Guaman Poma repetidamente declaró, y el resultado de esa injusticia había sido el caos y la miseria en los Andes. Por otro lado, los incas habían sido derrotados gracias a la intervención de la ayuda divina. El problema de un resultado injusto, detrás del cual estaba la mano de Dios, inmediatamente da lugar a preguntarse por qué pasaron las cosas de esta manera. Entre los españoles de la época dos ideas populares daban cuenta de esta pregunta. La primera era que, según la versión de los mismos conquistadores, ellos habían ejecutado la voluntad de Dios, lo que los convertía en elegidos divinos y esto era motivo de celebración. La segunda argumentaba que los indios se merecían la derrota como castigo a sus culpas y, por tanto, el resultado era moralmente correcto, independientemente de las consecuencias. Esta era, a menudo, la versión de la conquista defendida por los religiosos europeos. Ambas creencias justificaban la presencia y acciones de los conquistadores españoles. Argumento aquí que, tal como ocurrió con la discusión de la primera aparente incoherencia (el encuentro de los embajadores), la solución a la lectura inconsistente de la intervención divina a favor de los españoles tenía que ver con un uso decolonial de la teología que cuestionaba las líneas raciales tal y como eran comúnmente imaginadas.

La expresión "la mano de Dios" se usa comúnmente para transmitir la idea de intervención divina, aunque los autores españoles la usaron poco en sus narrativas. Empleo aquí la frase "la otra mano de Dios" para resaltar que la forma en que Guaman Poma le dio sentido a la intervención divina difirió de la interpretación de otros autores en su época. El elemento crucial para que "la mano de Dios" se manifieste y se comprenda es el concepto de gracia, quién la merecía y por qué. Contestar estas preguntas de una forma diferente a lo que se había hecho 
hasta su momento, le permitió al autor andino dar una interpretación alternativa de por qué los incas habían sido derrotados con ayuda divina, y este argumento obligaría a sus lectores a reconsiderar su lugar en el mundo en el pasado y, más aún, en el presente y futuro coloniales.

Guaman Poma comenzó la historia de la conquista adoptando explícitamente el marco providencial que forma parte de todas las narrativas españolas de este evento. Así, por ejemplo, el cronista indígena narró el momento exacto de la llegada española de este modo:

Y fue bentura y pirmición de Dios que, en tanta batalla y derramamiento de sangre y perdida de la gente deste rreyno, saliese los cristianos. Fue Dios seruido y la Uirgen María adorado y todos los sanctos y santa ángeles llamado de que fuese la conquista en tanta rrebuelta de Uascar, Atagualpa, Yngas. (p. 380)

La divina providencia hizo que los españoles llegasen cuando los ejércitos y las energías incas estaban enfocadas en la guerra de sucesión. Más adelante, otros milagros en momentos claves de la conquista debilitaron aún más la resistencia inca. Estas referencias a un Dios que se involucra directamente y cuyos medios y objetivos eran cognoscibles encajaban bien con la versión de la intervención divina defendida por los conquistadores: ellos eran los ejecutores de la voluntad de Dios. Cristóbal Colón inauguró el marco providencial en su diario del primer viaje a las Indias, ya que se presentó a sí mismo como el elegido de Dios (Valera, 1989, pp. 127, 134). En su informe oficial del descubrimiento (la "Carta a Luis de Santángel”), Colón justificó el éxito de su empresa como el resultado de la intervención divina. Es Dios quien había "dado victoria" al rey y a la reina, como siempre lo hacía con aquellos que "andan su camino" (en Valera, 1989, p. 145). De ahí en adelante, esta idea se repitió y se desarrolló en los textos colombinos y en las empresas de colonización que los siguieron, y se adaptaron sobre todo a episodios donde hubo despliegue de fuerzas militares.

En su primera carta de relación al rey, Hernán Cortés mencionó por lo menos tres actos de intervención de "la mano de Dios": i) evitó que la flota española zarpase de la isla de Cozumel, permitiendo que Jerónimo de Aguilar se 
reuniese con los españoles $(2002$, p. 58); ii) también ayudó a que una fuerza de 400 españoles derrotase un ejército de 40.000 indios en la batalla de Veracruz; y, iii) como colofón de lo anterior, permitió el descubrimiento y la conquista del imperio Azteca para que los indios pudiesen ser salvados (Cortés, 2002, p. 72). Esta interpretación se utilizó en varios relatos de la conquista del Perú, incluyendo la Verdadera relación de Francisco de Xerez, secretario de Francisco Pizarro. De acuerdo con esta relación, Dios había "permitido" que Atahualpa fuese capturado (Xerez, 1985 [1535], p. 113) y ayudó "con su divina mano" a todas las conquistas españolas (Xerez, 1985 [1535], p. 59).

Si bien los conquistadores usaron mayormente este tema para celebrar sus hazañas y reivindicar sus derechos a honores, recompensas y dominio, los clérigos lo utilizaron con fines didácticos, que incluían temas relacionados con el honor, las hazañas y el derecho a mandar sobre las almas de los conquistados. En dicho contexto se entiende el sermón 24 del Tercero catecismo y exposición de la doctrina cristiana, por sermones (1585) que declaraba que la conquista y sus consecuencias ocurrieron porque Dios quiso castigar a los indios por sus pecados pasados y presentes. El sermón comenzó por explicar por qué, a pesar de ser actos prohibidos, la fornicación y el adulterio ocurrían y Dios no castigaba a todos los infractores. La respuesta a este dilema era ambivalente. Por un lado se entendía como un asunto individual que eventualmente se resolvería: si Dios no castigaba estos pecados de forma inmediata era solo porque enviaría un castigo aún más duro a medida que los pecados se acumulasen. Por otro lado, el castigo se extendía a la colectividad: en tanto que un infractor podía no ser castigado en el acto, su pueblo en conjunto podía serlo. Luego de presentar varios ejemplos bíblicos de castigo colectivo, el sermón utilizó este argumento para explicar el estado de cosas en los Andes coloniales:

Sepa que la causa porque Dios ha permitido que los indios seáis tan afligidos y acosados de otras naciones, es por ese vicio [sodomía] que vuestros antepasados tuvieron, y muchos de vosotros todavía tenéis. Y sabed que os digo de parte de Dios que si no os enmendáis, que toda vuestra nación perecerá. Y os acabará Dios y os raerá de la tierra. (Tercero catecismo, 1990 [1575], p. 710) 
Más aún, el sermón señaló que incluso los pecados sexuales de los españoles eran culpa de los indios. Por ejemplo, los curas españoles tenían sexo con las indias porque ellas los seducían y esta seducción era particularmente reprehensible, ya que estas mujeres tentaban a hombres consagrados al servicio de Dios. En suma, aunque no celebraban los actos de los conquistadores, los religiosos invocaron el marco providencial para explicar el presente: todo lo malo que pasaba a los indios era culpa de ellos mismos, una forma de pensar que seguía la lógica del requerimiento.

Las denuncias vehementes que Guaman Poma hizo en su crónica se referían al abuso sexual de mujeres indias por españoles y la consecuente exterminación de la raza andina. Estos problemas habían sido presentados por el Concilio Eclesiástico de 1583 como el resultado de los errores de los indios y su estado deplorable era dictado por la voluntad de Dios. En este y otros casos, el catecismo usó ejemplos del pasado para justificar políticas eclesiásticas para corregir a los indios y enseñarles cómo ser buenos cristianos. De esta manera, las posiciones morales acerca de pecados y culpabilidad usaron la inversión del verdadero orden de las cosas y, en el pensamiento guamanpomiano, el concilio era la personificación de "el mundo al reués".

Para entender la forma en que Guaman Poma enfrentó este aparente acertijo (cómo explicar un resultado negativo con la ayuda de Dios), el primer elemento que los lectores tenían que considerar era el hecho de que los incas eran malos 5 . Por ejemplo, el cronista apuntó que su padre era indio yarovilca, una etnia conquistada por los incas. Esto, sin embargo, no explica por qué Guaman Poma no eligió identificarse con su madre, quien era de linaje real incaico. Después de todo, representar a los incas como gente que había arrastrado a los pueblos indígenas a la idolatría no se contradecía con la imagen positiva que la Nueva corónica expone acerca de los pueblos prehispánicos. Sugiero entonces que retratar a los incas como malignos respondió a la necesidad de dar una coherencia global a la narrativa histórica de la obra. Consistió en un medio para reconciliar dos hechos: el primero, que los andinos no adoraban a Dios cuando los españoles llegaron y, sin embargo, habían tenido una trayectoria ascendente como sociedad, 
y, el segundo, que ni a los indios les había faltado el favor divino antes de la conquista, ni eran "novatos" luego de la misma, como el Tercer Concilio de Lima declaraba $^{6}$. Los elementos claves que le permitieron a Guaman Poma solucionar esta aparente contradicción fueron el diablo, los milagros y la gracia.

$\mathrm{Si}$, en el razonamiento del cronista indígena, los pueblos andinos tempranos habían sido protocristianos o cristianos avant-la-lettre y, a diferencia de los españoles, se habían desarrollado sin límites ni desviándose del "camino moral correcto", entonces la única forma de introducir la idolatría era a través de un elemento foráneo. Invocar la presencia del diablo en el contexto de la historia universal era hasta cierto punto algo no problemático. De acuerdo con las historias de origen occidental, el mismo se había aparecido, tarde o temprano, a todos los pueblos del mundo en algún momento. Su presencia no señalaba necesariamente la ira de Dios o su abandono, pero sí tuvo un papel muy importante en la mayoría de las justificaciones españolas de la conquista, sea para celebrarlas (Verdadera relación de Xerez, 1535) o para criticarlas (Historia natural y moral de Acosta, 1590). La presencia del diablo en América sirvió al argumento de que los conquistadores y/o los clérigos habían traído la luz de la verdad y la salvación para derrotar al enemigo de Dios. El dilema para Guaman Poma era, por tanto, cómo conciliar la idolátrica alianza entre los incas y el diablo en una narrativa providencial alternativa. La solución del autor indígena fue convertir la conquista en un evento que había ocurrido para el bien de los pueblos andinos, aunque en sus propios términos.

Guaman Poma esperaba que sus lectores se dieran cuenta de que los efectos de la presencia del diablo eran distintos a cómo se presentaban en textos españoles. En la Nueva corónica el diablo evoca la idolatría, pero esta no era equivalente ni a la imagen del "error" de los indios (Las Casas) ni a la imagen de un diablo que fácilmente "engañaba" a unos indios crédulos (Acosta). Significaba, en cambio, la opresión de la verdadera y persistente voluntad de los indios que continuaron reverenciando a Dios mientras eran forzados a adorar a las huacas incaicas. Este argumento dejaba en claro el hecho de que los indios no habían sido engañados y transformados en títeres inconscientes del diablo antes de la llegada de los conquistador (pp. 237-302). Dicho de otro modo, aun si habían sido gobernados por idólatras como los incas, los indios no se habían convertido en idólatras. 
El segundo elemento que los lectores debían tener en cuenta para entender "la otra mano de Dios" era la serie de milagros durante las batallas de la conquista. Las páginas de la Nueva corónica mencionan milagros importantes que tuvieron lugar durante el cerco del Cuzco liderado por Manco Inca en 1536-1537. No todos los relatos españoles de este evento mencionaban milagros, por lo que Guaman Poma podría haber elegido no hacerlo ${ }^{7}$. ¿Por qué decidió incluirlos? Una respuesta posible es que la ocurrencia de milagros le permitía rebatir las explicaciones de los proponentes de la tesis que, al no haber presenciado milagros, los indios no habían podido ser persuadidos a aceptar el cristianismo cuando les era presentado por primera vez. Otra razón posible para la inserción de milagros en la obra de Guaman Poma podría ser su intento de rebatir a teólogos más tardíos, como José de Acosta, quienes señalaban que los indios eran en general gente tan baja que los milagros no eran necesarios para que la superioridad cristiana (y española) fuera clara. Esta concepción de los indios los diferenciaba de lo que había ocurrido con los griegos y los romanos que habían rechazado el cristianismo en los tiempos de los apóstoles (Adorno, 2000, p. 31).

Sea una u otra razón, la inclusión de milagros no estaba exenta de problemas ya que contribuía a la celebración narrativa de la mano de Dios. A fin de cuentas, Dios habría ayudado a los españoles. Hay en la Nueva corónica, sin embargo, un detalle que proponía una interpretación radicalmente distinta: los milagros no habían ocurrido para que los españoles ganasen sino para que los incas perdiesen las batallas. Así, los indios — sin los incas — podrían haber ganado, una opción que ningún autor español consideró ni siquiera remotamente. Consideremos la aparición de la Virgen María durante el cerco del Cuzco cuya ilustración antecede al texto (figura 2, "MILAGRO DE S[AN]TA M[ARÍ]A/en el Cuzco"): "de uelle se espantaron los yndios y dizen que le echaua tierra en los ojos a los yndios ynfieles. Cómo Dios hizo milagro para hazelle merced y su madre bendita a los españoles cristianos" (p. 405). Hasta aquí el texto parece sostener las lecturas tradicionales de los milagros y la mano de Dios. Pero el párrafo continúa con una aclaración: "por mejor dezir que más quiso hazer merced la Madre de Dios a los yndios porque fuesen cristianos y saluasen las ánimas de los indios". Si los incas hubieran ganado la batalla por el cerco del Cuzco, el dominio incaico habría continuado y, con este, la idolatría. 


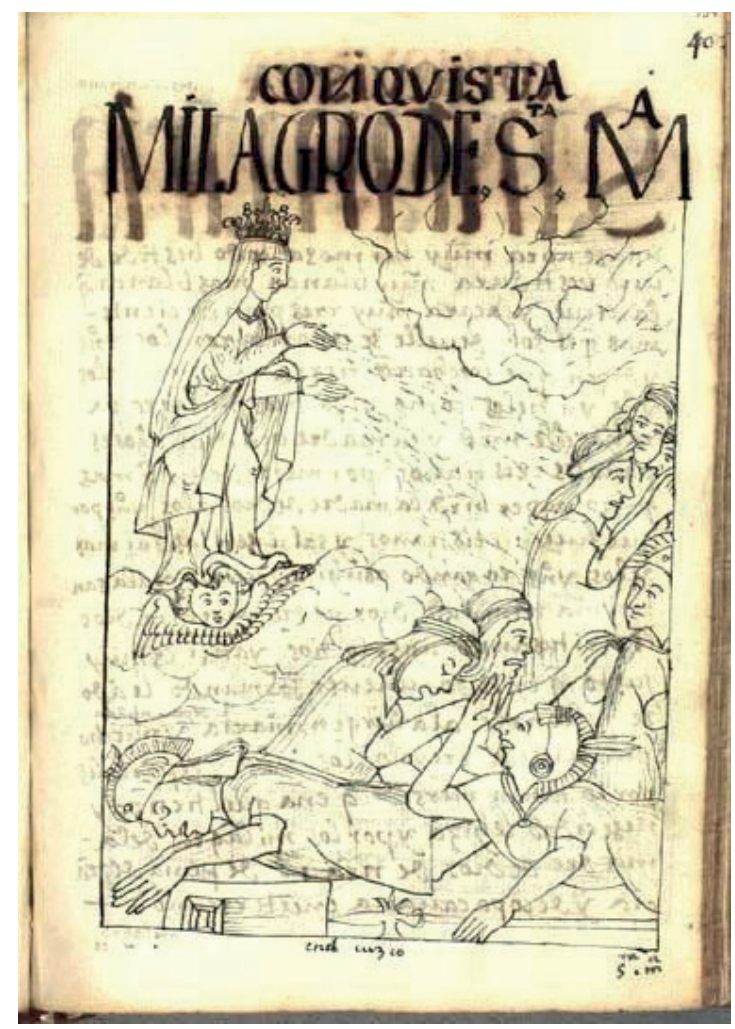

Figura 2. Nueva corónica y buen gobierno (1615), p.

404. Biblioteca Real de Copenhague, Dinamarca.

Considerando su forma de concebir la idolatría de los pueblos indígenas del Perú, era lógico que la intervención divina durante la conquista tuviese como principales destinatarios del favor divino a los indios y no a los españoles. Los primeros eran agradables a Dios, quien expresaba su amor por ellos a través de su ayuda. Los últimos eran solo peones con una función específica: eliminar a los incas, pero llevar a cabo esa tarea no los hacía partícipes de la gracia de Dios ${ }^{8}$. De hecho, uno puede argumentar que los milagros eran medios a través de los cuales Dios les recordaba su presencia a los conquistadores españoles, para que estos se comportasen como buenos cristianos.

Igualmente importante fue el hecho de que el objetivo divino no era ayudar a los españoles a convertir indios, sino ayudar a los indios a que 
practicasen su cristianismo y no la idolatría que los incas les habían impuesto. Esta forma de narrar los milagros durante la conquista no formaba parte del horizonte conceptual de autores españoles. Por eso, entre un tono burlesco y un tono serio, Guaman Poma incluye una versión quechua del Credo indígena para pedir a Dios protección, no solo de los enemigos usuales, sino también de los corregidores, curas y otros oficiales coloniales: "Justicia cunamanta corregidor, alguazil, jueses, pisquicidores, padre, comendero, escriuano, mayordomo, teniente, tanbo uira cocha, runa llatanac, suuaconamanta uacaychauay. Diospa maman uacaychauay" [Protégenos de los justicias, corregidor, alguacil, jueces, pesquisidores, padre, encomendero, escribano, mayordomo, teniente, españoles del tambo, despojadores de hombres y ladrones] (pp. 849-851).

Esta solución difería también de la posición de los cronistas con influencia lascasiana: los mensajeros españoles eran indignos portadores del mensaje pero, por lo menos, lo habían entregado. En el texto de Guaman Poma, en cambio, los españoles no solo no habían estado a la altura del mensaje, sino que no lo habían entregado. No hay contradicción alguna en esta postura, como sí era el caso de la crítica interna española que sostenía el privilegio europeo. Por ello, el cronista andino manifestaba que, si los españoles hubiesen llegado justo antes de que el dominio inca comenzase, los indios habrían sido santos: "Ci luego le enbiara Dios a sus profetas y apóstoles, fueran santícimos honbres que no los enbiara la más peruersa animal que la de los españoles” (p. 61). En la línea de reflexión del autor indígena, los indios conocían a Dios y habían tenido siempre el mejor orden posible, a pesar de todos los obstáculos de la idolatría. En suma, la conquista no tenía justificación, excepto en la visión de los españoles.

El tercer y último elemento para que los lectores apreciaran "la otra mano de Dios" fue la gracia que, en la Nueva corónica, se concede únicamente a indios. El Espíritu Santo aparece en forma activa solo en tres de las 398 imágenes del libro: descendiendo sobre Martín de Ayala, el hermano y maestro de Guaman Poma (figura 3: "Martin de Ayala, hermitaño / don Martin Ayala, excelentísimo señor, p[r]incipe / doña Juana Curi Ocllo, coya [reina] / en la ciudad del Cuzco"); descendiendo sobre unos indios pobres que están rezando en una iglesia (figura 4: "Evangelista sagrada escritura uillascayque, churicona. Uaca uilcataca manam 
sermoyquicho. Chaytaca naupa machoyque chi yacharca. Camca bautisacca nam canque, churi" [Hijos míos, les voy a anunciar el evangelio, la sagrada escritura. No deben servir a las divinidades locales. Antes, sus antepasados vivieron así, pero ustedes ahora ya están bautizados, hijos]); y descendiendo sobre una mujer india que está rezando ante una imagen de Cristo (figura 5: "Christiana"). No hay dibujo que muestre al Espíritu Santo sobre un español.
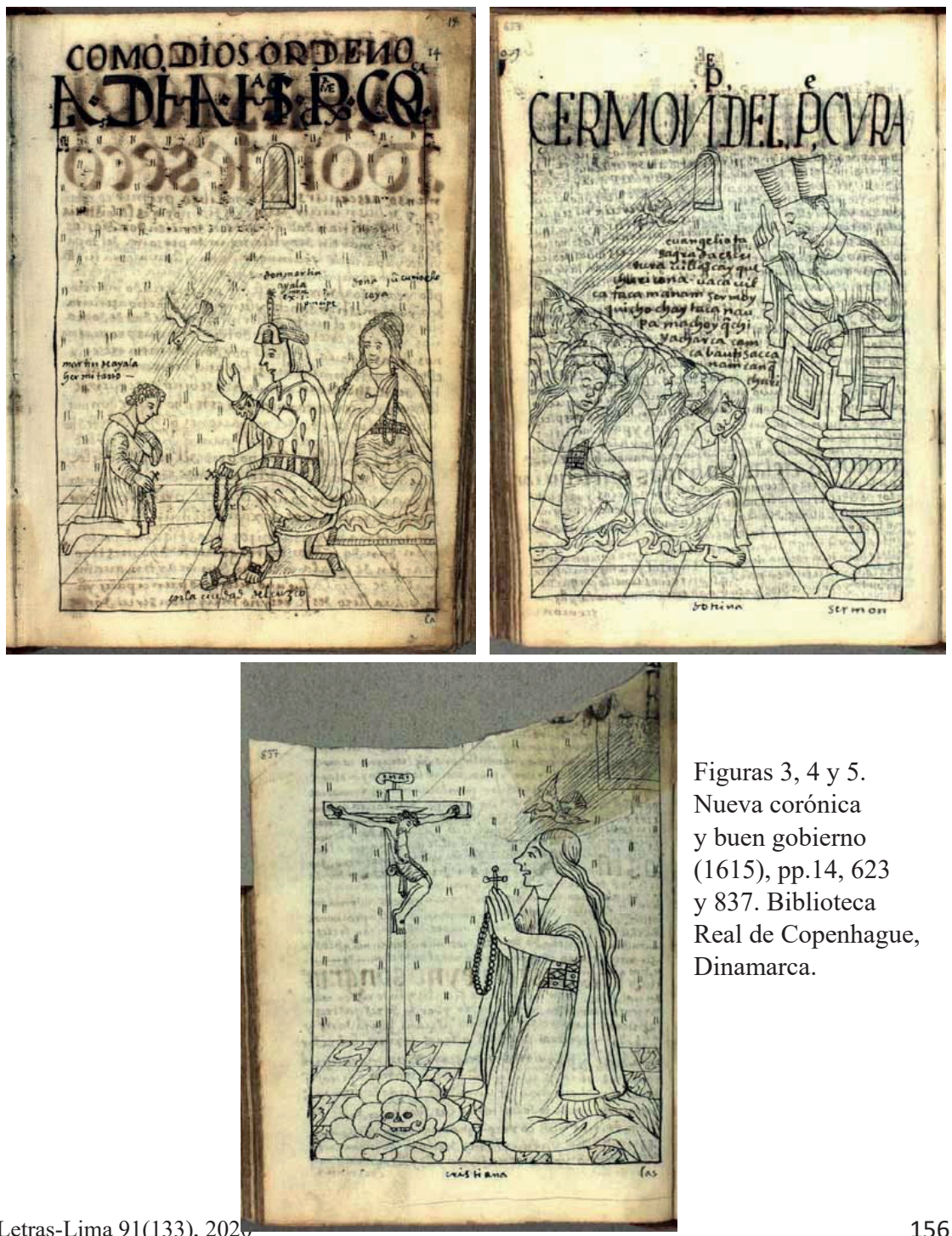

Figuras 3, 4 y 5.

Nueva corónica y buen gobierno (1615), pp.14, 623 y 837. Biblioteca Real de Copenhague, Dinamarca. 
El hecho de que estas sean las únicas instancias en que el Espíritu Santo desciende sobre personas, y que esas personas solo sean indios y reciban la gracia de Dios, no debe ser minimizado. La gracia no solo es significativa como manifestación puntual y extraordinaria de lo divino — esto es cierto también de los milagros-, sino que es elemento central del régimen de inteligibilidad alternativa que la Nueva corónica propone a sus lectores. La idea de gracia que maneja Guaman Poma parte de la obra de fray Luis de Granada que conocía muy bien. En su Memorial de la vida cristiana (1565), el dominico señaló repetidamente que de los dos elementos que deben tenerse en cuenta para "el bien vivir", objetivo último de un cristiano, "saber" era más importante que "poder hacer" (Granada, 1994-1995, II, pp. 15-16) . Ante la pregunta ¿por qué hace el hombre algo mal si sabe que está mal?, Granada responde: porque no puede evitarlo. Como resultado de la caída, ningún hombre puede hacer lo correcto todo el tiempo, ya que es imperfecto y eso excedería su poder natural. Para superar esta limitación, el hombre necesita un suplemento sobrenatural que es la gracia.

El maestro granadino dedicó gran parte de su Memorial a resolver dudas sobre la gracia. ¿En qué condiciones puede Dios darla o quitarla? ¿Cuáles son los medios a través de los cuales el hombre puede acceder a la gracia? ¿Cómo funcionan estos medios exactamente? Como sucede con el "lector cristiano", hacer que estas cuestiones teológicas fueran relevantes para una discusión de problemas coloniales alteró completamente el orden local de las cosas. En el texto de Granada, la cuestión de la gracia es un asunto personal, individual, no es racial ni étnico. Todos los hombres se enfrentan a los mismos problemas y están en la misma situación. Esta idea no era problemática en la Península, pero en el contexto andino era altamente controversial, ya que cuestionaba la piedra angular del colonialismo: la diferencia entre españoles e indios. Omitirla implicaba tratar a los indios de manera diferente, pero seguirla suponía que cualquier hombre (independientemente de que fuera indio, español o negro) podía acceder a la gracia de Dios.

La cuestión de la gracia es central para entender el acertijo del presente colonial en el que escribe Guaman Poma. ¿Cómo reconciliar "la mano de Dios" con el sufrimiento de los indios y la impunidad de los españoles? La gracia - y con 
esta la compasión - se alteran en el contexto colonial. El cronista andino alertó a sus lectores cristianos de que no sacasen conclusiones apresuradas. Los milagros, les dijo, pueden referirse a muchas cosas distintas: desde Dios comprobando la existencia de caridad entre los indios hasta los terremotos; desde pestes como la viruela o las paperas hasta tormentas de nieve extraordinarias; desde cosechas que se congelan a invasión de ratones y otras plagas. Los milagros incluían, en una combinación titilante de sarcasmo y declaración sin rodeos, que Dios enviase "malos critianos a rrobar hazienda de los pobres y quitalles sus mujeres y a sus hijas y seruirse de ellas" (p. 95) porque es una manera de salvar el alma:

[c]on todo eso nos dize Dios que nos acordemos y llamemos, y en cada hombre y en cada casa enbía Dios al mundo su castigo para que lo llamemos y denos gracia para que nos lleue a su gloria adonde uiue la Santícima Trinidad. (p. 95)

Rogar a Dios era, según Granada, la forma más eficiente para acceder a la gracia. Guaman Poma se hace eco de esta idea numerosas veces a lo largo de su obra. Dicha línea de pensamiento teológico permitía interpretar el cerco del Cuzco como un ejemplo de intervención divina favorable a los indios. Asimismo, los milagros tuvieron lugar no para mover a los indios a convertirse a una nueva religión, ni para ayudar a los españoles en tanto elegidos de Dios, como las lecturas reduccionistas de los textos coloniales afirmaban. Los milagros en las batallas de conquista sucedieron para ayudar a los indios a liberarse de los incas $\mathrm{y}$, eventualmente, para recordar a aquellos que se llamaban a sí mismos cristianos (pero no se comportaban como tales) lo que realmente significaba ser cristiano.

Esta forma teológica alternativa de pensar la intervención divina en la conquista del Perú también explicaba, en términos distintos a los del Concilio, por qué Dios podía elegir no castigar a aquellos que hacían el mal y no recompensar a los que hacían el bien. En el primer caso, Dios podía permitir que los pecadores se perdiesen irremediablemente para que su castigo eterno fuese el más duro y el más definitivo, tal como explicaba Granada:

El castigo que merecen estos es el que Dios les da, que es el mayor que se puede dar, que es dejarlos andar en este juego toda la vida hasta 
que llegue la muerte, donde les acaezca lo que suele acaecer a los que nunca hicieron penitencia verdadera. (1994-1995 [1565], I, p. 65)

En el segundo caso, Dios podía dejar sufrir a los que hacían buenas obras para poner a prueba su fe, paciencia y perseverancia ante la adversidad, queriendo que sintiesen su "desamparo" y "olvido", rezasen pidiendo ayuda y así serían recompensados con el premio mayor (Granada, 1994-1995 [1565], II, pp. 51-55). Mientras el sermón 24 del Concilio mencionaba la ausencia del castigo a los que hacían el mal, no consideraba la segunda (no recompensar a los que hacían el bien) y más bien justificaba el presente colonial de los indios como consecuencia de (supuestos) pecados pasados.

A estas formas teológicas alternativas de interpretar la intervención divina, con sus consecuencias importantes en función de la inteligibilidad de la historia, Guaman Poma le agregó un par más a medida que el texto progresó. En las "Conzideraciones", le dijo a los lectores españoles en particular otra razón por la que no había castigo: había muchas plegarias efectivas pidiéndole a Dios perdón y misericordia. "Santa María Peña de Francia ruega a su hijo señor Jesucristo, y los santos y santas, ángeles del cielo, por el mundo y por lo pecadores" (pp. 946, 1026). Finalmente, debían considerar también las plegarias de "los questá en el mundo, de los santos saserdotes, clérigos, frayles y hermitaños y otros que no traen áuito, santos y santas señoras del mundo" (pp. 947, 1028).

En conclusión, la historia de los Andes no era como los autores españoles la presentaban. Los actos de Dios no eran legibles solo en las formas en que estos autores ubicuamente declaraban. Una interpretación teológicamente sólida de la historia providencial y la gracia divina, basada en autoridades cristianas altamente respetadas, resultaba en una historia totalmente diferente. De comprender esta distinción entre interpretaciones teológicas de una historia local y una historia universal se derivaban consecuencias claras para entender el presente y el futuro de los indios del Perú. Los conquistadores y autores españoles quitaron efectivamente a los incas del mapa de la historia global. Por ello, se hacía necesario andar nuevamente por el camino (estrecho) de la historia universal, 
camino en el cual los pueblos andinos siempre habían estado delante de los españoles. En este sentido podemos entender la conversación que tenía lugar hacia 1615 y que informó la producción textual de Guaman Poma. Se trataba entonces no de apuntar errores (por ejemplo, la idolatría de los indios) para erradicarlos, como el discurso colonial español declaraba y las campañas de extirpación ponían en práctica, sino sobre cómo ser y dejar ser lo que debía ser en la historia andina.

\section{Notas}

1 Todas las citas textuales provienen de la edición digital, con paginación corregida, que se puede consultar aquí: http://www.kb.dk/permalink/2006/poma/info/en/frontpage. htm (Guaman Poma, 2001 [1615]). Cuando nos refiramos a esta obra solo citaremos el número de página.

2 Cuando la compañía española llega a Tumbes, Atahualpa había enviado allí a un inca de alto rango, quien era tanto un delegado especial como un espía. Guaman Poma no hace referencia alguna a la incertidumbre y las especulaciones sobre quiénes eran los españoles, que otras fuentes dejan en claro (véase Lamana, 2008, capítulo 1).

3 En los capítulos sobre el tiempo prehispánico, Guaman Poma menciona que las huacas y hechiceros de los incas les habían hablado del Viejo Mundo (Roma, Castilla, Turquía) (pp. 111, 114) y también que los reyes incas habían profetizado la llegada de gente nueva (pp. 264, 380). Guaman Poma plantea un razonamiento similar al del cronista texcocano Alva Ixtlilxochitl (2000 [1640?]): los amerindios siempre fueron parte de la historia universal y la conocían. El recurso a las profecías (algo a menudo polémico entre los estudiosos del colonialismo occidental) no es evidencia de mal agüero o prueba de inferioridad, sino una forma de cuestionar la geopolítica occidental del conocimiento según la cual se organizan los textos occidentales.

4 El requerimiento fue usado por primera vez en 1513 por Pedro Arias (Pedrarias) en América. El texto que se usaba fue escrito por el jurista y consejero real Juan López de Palacios, autor del Tratado de las islas (1512). Inspiró además buena parte de la legislación española para América y difundió la idea de la inmadurez de los indios, a quienes se debían proteger de ellos mismos. Era una declaración del rey español que se leía a los indios para informarles del derecho que tenía España para conquistarlos. Si los indios se resistían a esta declaración, los españoles lo consideraban un desafío a la voluntad de Dios y esto justificaba su derecho a la guerra de conquista. El texto completo del requerimiento se puede consultar en: https://web.archive.org/ web/20070501102909/http://www.ciudadseva.com/textos/otros/requeri.htm.

5 Esta observación necesita clarificación. Los incas no eran simplemente malos según lo que planteaba Guaman Poma. Siguiendo un esquema creado por Polo Ondegardo y repetido por Acosta (Lamana, 2012), el autor andino distinguía el dominio inca en función del "buen gobierno" y de la "mala religión". Una relación cercana con el diablo habría resultado en el inicio de la idolatría en los Andes. Pero, por otro lado, los incas eran el mejor ejemplo de buen gobierno y sus leyes que seguían de cerca a la ley natural. 
6 Tercero catecismo: "gente nueva en la fe" (1990, p. 625) o gente "de cortos y tiernos entendimientos" (p. 625).

7 Para la emergencia de la tradición milagrosa, véase Duviols, 1962.

8 Las narrativas españolas (Colón, Cortés, Xerez) presentan los triunfos de los conquistadores como el resultado de la intervención divina y la fe del héroe en Dios. Hay un círculo virtuoso en el cual las buenas obras son recompensadas con gracia que fortifica al héroe para que realice nuevas y más grandes hazañas. En contraste, no hay héroes en estas batallas en la Nueva corónica. Además, los conquistadores son presentados de la forma más desfavorable posible. Por lo tanto, sería claro para el lector que no podía haber círculo virtuoso alguno. Por ello, los actos de intervención divina según Guaman Poma, y a diferencia de los textos españoles, tuvieron protagonistas estrictamente divinos: la Virgen María, Santiago Matamoros, el Espíritu Santo, entre otros. El fin de los conquistadores deja claro que estos no iban a ser recompensados en la vida después de la muerte (una declaración teológica), de la misma manera que no deberían recibir ningún premio en la vida terrenal (una declaración política).

9 "Entre estas dos partes que para bien vivir son necesarias, la segunda es tanto más necesaria y excelente que la primera cuanto lo es más el espíritu que el cuerpo, y el evangelio que la ley" (II, pp. 15-16).

\section{Referencias bibliográficas}

Acosta, J. de. (2002 [1590]). Historia natural y moral de las Indias. Madrid: Dastin.

Adorno, R. (2000 [1986]). Guaman Poma: Writing and Resistance in Colonial Peru. Austin: University of Texas Press.

Cortés, H. (2000). Cartas de relación. Madrid: Dastin.

Duviols, P. (1962). Les traditions miraculeuses du siège du Cuzco (1536) et leur fortune littéraire. Bulletin de la Faculté des Lettres de Strasbourg, 40(7), $1-7$.

Granada, L. de. (1994-1995 [1565]). Memorial de la vida cristiana. Obras completas, vols. I y II. Madrid: Fundación Universitaria Española.

Guaman Poma de Ayala, F. (1987 (1615)]. Nueva crónica y buen gobierno. Edición a cargo de J. V. Murra, R. Adorno y J. L. Urioste. Madrid: Historia 16.

Guaman Poma de Ayala, F. (2001 [1615]). El sitio de Guaman Poma. Nueva corónica y buen gobierno. Copenhague: Biblioteca Real. Recuperado de http://www.kb.dk/permalink/2006/poma/info/en/frontpage.htm 
Ixtlilxochitl, F. de A. (2000 [ca. 1640?]). Historia de la nación Chichimeca. Madrid: Dastin.

Lamana, G. (2008). Domination without Dominance. Durham: Duke University Press.

Lamana, G. (2012). Pensamiento colonial crítico. Polo Ondegardo, los Andes y los estudios andinos. En Go. Lamana (Ed.), Pensamiento colonial crítico: Textos y actos de Polo Ondegardo (pp. 49-87). Lima-Cuzco: Instituto Francés de Estudios Andinos, Centro de Estudios Regionales Andinos Bartolomé de Las Casas.

Lamana, G. (2016). Colonialidad y teología en la obra de Guaman Poma de Ayala. En C. Poupeney Hart et ál. (Eds.), El Perú en su historia. Fracturas y persistencias (pp. 149-166). París: Editions Le Manuscript.

Las Casas, B. de. (1992 [1552]). Brevísima relación de la destrucción de las Indias. Edición de Ramón Hernández. En P. C. Delgado y A. García del Moral (Eds.), Obras Completas, vol. 10 (pp. 29-94). Madrid: Alianza Editorial.

Tercero cathecismo y exposición de la doctrina cristiana, por sermones. (1990 [1585]). En J. G. Durán(Ed.), Monumenta catechetica hispanoamericana, vol. II (pp. 613-741). Buenos Aires: Pontificia Universidad Católica Argentina.

Valera, C. (Ed.). (1989). Cristóbal Colón. Textos y documentos completos. Madrid: Alianza Universidad.

Xerez, F. de. (1985 [1535]). Verdadera relación de la conquista del Perú. Madrid: Historia 16. 